\title{
ANÁLISE DO COMPORTAMENTO DE REJEITO DE CERÂMICA VERMELHA COMO FONTE DE POTÁSSIO NO CULTIVO DE BANANEIRA
}

\section{L. S. Nobre', J. Y. P. Leite', M. F. B. Dutra' ${ }^{2}$, A. J. R. P. Medeiros ${ }^{2}$ e E. C. Pereira ${ }^{2}$}

'Laboratório de Processamento Mineral - Instituto Federal do Rio Grande do Norte

${ }^{2}$ Laboratório de Biotecnologia - EMPARN

lanalopesrnl@hotmail.com - jyp.leite@ifrn.edu.br

\section{RESUMO}

Rochas ricas em potássio (K) vêm sendo utilizadas como alternativa tecnológica ao uso desmedido de produtos químicos na agricultura, aumentando a fertilidade do solo sem comprometer o equilíbrio do meio ambiente, podendo ainda configurar-se como uma opção a disposição de alguns tipos de rejeitos de processo.

Para a realização desse trabalho, analisou-se o potencial do rejeito da cerâmica estrutural como fonte de potássio. Amostras do rejeito foram coletadas e submetidas a processo de moagem em moinho de martelos até atingir $100 \%$ passante em malha de $2 \mathrm{~mm}$. O material foi em seguida submetido a análise química por fluorescência de raios- $x$, apresentando em média 3\% de potássio. O pó do rejeito, assim denominado, foi aplicado diretamente em mudas de bananeiras para avaliar o desenvolvimento e absorção do K. Resultados mostram que a absorção do nutriente $K$ está na faixa necessária para o cultivo de bananeira.

PALAVRAS-CHAVE: Rejeito de cerâmica, cerâmica estrutural, fertilizantes agrícolas

\section{ABSTRACT}

Rocks rich in potash (K) has been used as a technological alternative to indiscriminated chemistries usage in agriculture, enhancing the soil fertility without compromise the environmental balance, configuring itself as an option to disposition of some processes wastes. In this work was analised the potencial of structural ceramic waste as potash source. Samples of ceramic tailings were collected and submited to grinding at hammer mill until $100 \%$ passing at $2 \mathrm{~mm}$. Chemical analyses by $\mathrm{x}$-ray fluorescence presented an average grade of $3 \%$ potash. The material denominated tailing powder was applied directly in bananas budding to evaluate its development and $\mathrm{K}$ absorption. Results show absorptions compatible to banana plant development. 


\section{ANÁLISE DO COMPORTAMENTO DE REJEITO DE CERÂMICA VERMELHA COMO FONTE DE POTÁSSIO NO CULTIVO DE BANANEIRA}

\section{INTRODUÇÃO}

Em nosso país, a agricultura é o setor mais importante da economia contribuindo com aproximadamente $30 \%$ do produto interno bruto nos últimos 10 anos (Lopes-Assad \& Almeida, 2004).

Os solos brasileiros são tipicamente intemperizados, com baixo teor de nutrientes, sendo o Potássio (K) o segundo macronutriente em quantidade utilizado no manejo da adubação das culturas, ficando atrás somente do Fósforo (P). As plantas utilizam a forma solúvel do $\mathrm{K}$, que é facilmente lixiviada, explicando a carência deste macronutriente em solos de cerrado ou sujeitos a muita chuva, como nas áreas tropicais.

O K no solo é usualmente distinguido nas formas: potássio na solução do solo; potássio presente na rede cristalina de minerais primários como micas e feldspatos e secundário como ilita, bem como o potássio fixado entre camadas de argilominerais do tipo 2:1 expansivos como a vermiculita e a esmectita (CURI et al., 2005)

O K trocável possui maior velocidade de liberação, pois envolve uma simples reação de troca da superfície dos coloides (NACHTIGAL; VAHL, 1991b). O K entre camadas das argilas 2:1 é liberado com maior dificuldade, pois depende de várias reações de troca, da expansão da argila e da difusão do elemento de posição entre as camadas estruturais de argila até a superfície externa (REICHENBACH, 1972). O potássio também pode ser liberado das camadas dos minerais 2:1 pela dissolução, particularmente promovida pela acidificação da rizosfera, devido à excreção de $\mathrm{H}^{+}$pelas raízes das plantas (SINGH; GOLDING, 1997)

Em virtude da pequena produção interna, comparada à grande demanda do produto, - Brasil situa-se no contexto mundial como grande importador de potássio fertilizante, tendo como principais fornecedores em 2010, a Bielorrússia $(28,01 \%)$, o Canadá (27,16\%), a Alemanha (17,7\%), Israel (14,24\%) e a Rússia (6,37\%) (DNPM, 2011).

A quantidade de potássio fertilizante importada em 2010 foi de 77,64\% acima da verificada no ano de 2009, enquanto o valor de importação do produto foi $7,46 \%$ maior que em 2009. O consumo brasileiro de potássio fertilizante mantém-se em um patamar elevado, confirmando assim a situação do Brasil no contexto mundial como grande consumidor e importador desse produto.

A Tabela 1 apresenta os números relacionados à produção, importação e exportação referentes ao cloreto de potássio no Brasil. 
Tabela 1 - Estatísticas de produção, importação e consumo de cloreto de potássio no Brasil.

\begin{tabular}{|c|c|c|c|c|}
\hline DISCRIMINAÇÃO & UNIDADE & 2008 & 2009 & 2010 \\
\hline PRODUÇÃO & $\left(\mathrm{t} . \mathrm{K}_{2} \mathrm{O}\right)$ & 382.257 & 452.698 & 417.990 \\
\hline \multirow{2}{*}{ IMPORTAÇÃO } & $\left(\mathrm{t} . \mathrm{K}_{2} \mathrm{O}\right)$ & 4.050 .464 & 2.068 .305 & 3.674 .186 \\
\hline & 103 US\$. FOB & 3.828 .375 & 2.079 .022 & 3.674 .186 \\
\hline \multirow[b]{2}{*}{ EXPORTAÇÃO } & $\left(\mathrm{t} . \mathrm{K}_{2} \mathrm{O}\right)$ & 10.316 & 8.317 & 12.880 \\
\hline & $10^{3}$ US\$. FOB & 11.840 & 9.312 & 9.863 \\
\hline $\begin{array}{l}\text { CONSUMO } \\
\text { APARENTE }^{(2)}\end{array}$ & $\left(\mathrm{t} . \mathrm{K}_{2} \mathrm{O}\right)$ & 4.423 .405 & 2.494 .501 & 4.079 .296 \\
\hline PREÇO ${ }^{(3)}$ & US\$ FOB/t. $\mathrm{K}_{2} \mathrm{O}$ & 954,17 & $1.005,20$ & 608,10 \\
\hline
\end{tabular}

Fontes: MDIC/SECEX - DNPM/DIPLAN. Nota: Referente ao cloreto de potássio com 60,0\% de K2O; (NCM 3104.20.10); (NCM 3104.20.90); (2) Produção + Importação - Exportação; (3) Preço médio FOB anual das importações brasileiras; (p) Preliminar, (r) Revisado.

Sendo o K um recurso não renovável e visando reduzir o custo de produção e os impactos negativos na balança comercial brasileira, no que se refere ao uso de adubos químicos, é preciso estudar formas de uso mais eficientes, técnicas que permitam recicla-lo no sistema (plantio direto) e fontes alternativas como utilizar rochas in natura diretamente no solo.

Décadas atrás foram desenvolvidos vários estudos no Brasil que utilizavam rochas para o fornecimento de $\mathrm{K}$ as plantas. Tentou-se desenvolver processos físicos e químicos de tratamento de rochas brasileiras com teores mais elevados de $\mathrm{K}$, o processo se mostrou economicamente inviável devido ao elevado gasto energético do processamento das rochas ou pela baixa competitividade em relação ao cloreto de potássio.

Novas tentativas de obter fontes alternativas do nutriente vêm sendo feitas. É objetivo do trabalho, analisar o potencial do rejeito de cerâmica estrutural como fonte alternativa de K. O trabalho foi desenvolvido pelo Laboratório de Processamento Mineral (LabPROM) do IFRN e pela EMPARN.

\section{MATERIAIS E MÉTODOS}

\section{Rejeito de Cerâmica Vermelha}

O rejeito estudado, foi submetidas a processo de moagem em moinho de martelos até atingir $100 \%$ passante em malha de $2 \mathrm{~mm}$. Após esse processo, o rejeito passou a ser denominado como "pó do rejeito" e levado para análise de Fluorescência de raios- $X$ com o equipamento EDX 720 da Shimadzu.

\section{Preparação das mudas de bananeiras}

As mudas de bananeiras foram preparadas na EMPARN e obedeceram o fluxograma apresentado na Figura 1. 


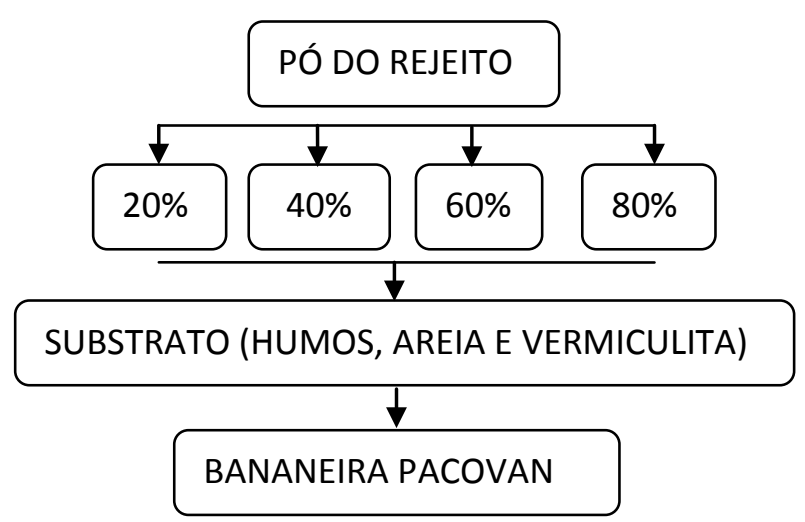

Figura 1. Fluxograma de preparação para o plantio das bananeiras.

O substrato usado pela EMPARN é composto por $45 \%$ areia, $45 \%$ humos e $10 \%$ vermiculita. Essa última passou a fazer parte do substrato depois que estudos realizados na empresa mostraram que esse argilomineral apresenta elevada capacidade de troca catiônica, de médio a alta concentração de cálcio, magnésio e potássio proporcionando aumento dessas bases para o solo, melhorando o crescimento e desenvolvimento das plantas. Além disso, possuem capacidade de absorção de água podendo ser utilizada pelas plantas no período de estiagem, sendo também ótimos condicionadores de solos ácidos e argilosos, tornando-os mais soltos, porosos e arejados, propiciando, desta forma, um melhor desenvolvimento de suas raízes.

Em uma bandeja, foram colocadas cinco fileiras de substrato ao qual foram adicionados, em cada uma, porcentuais diferentes do pó do rejeito, como mostra a Figura 2. Após a mistura, as mudas de bananeira pacovan ken foram plantadas. As mudas eram constantemente observadas para avaliação do crescimento. Após o primeiro mês, foi medida a altura de cada muda, sendo comparada esta medida com a muda que não recebeu o pó do rejeito. Fragmentos das folhas foram levados para análise de macronutrientes no laboratório de análise de água, solo e planta da Empresa de Pesquisa Agropecuária do Rio Grande do Norte (EMPARN).

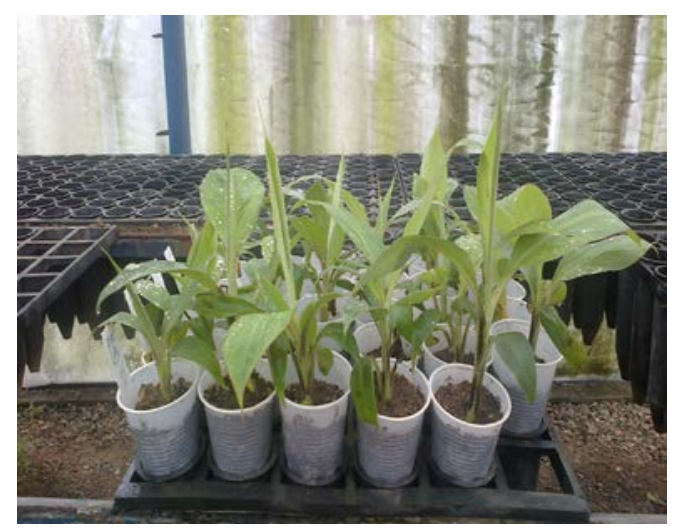

Figura 2 - Plantio de muda de bananeiras 


\section{RESULTADOS E DISCUSSÕES}

\section{Análise química}

A Tabela 2 apresenta os resultados da análise química por fluorescência de raios-x.

Tabela 2 - Composição química do rejeito de telha estudado

\begin{tabular}{cc}
\hline Elementos & $\%$ \\
\hline $\mathrm{SiO}_{2}$ & 47,46 \\
$\mathrm{Al}_{2} \mathrm{O}_{3}$ & 23,04 \\
$\mathrm{Fe}_{2} \mathrm{O}_{3}$ & 17,72 \\
$\mathrm{~K}_{2} \mathrm{O}$ & 3,80 \\
$\mathrm{MgO}$ & 3,13 \\
$\mathrm{CaO}$ & 2,36 \\
$\mathrm{TiO}_{2}$ & 1,74 \\
$\mathrm{MnO}$ & 0,21 \\
$\mathrm{P}_{2} \mathrm{O}_{5}$ & 0,13 \\
\hline
\end{tabular}

$\mathrm{O}$ valor encontrado para $\mathrm{SiO}_{2}$ e $\mathrm{Al}_{2} \mathrm{O}_{3}$ correspondem a mais de $70 \%$ do total dos compostos apresentados, sendo o $\mathrm{SiO}_{2}$ em maior quantidade. Nota-se que, em termos de nutrientes, a amostra apresenta $3,80 \%$ de $\mathrm{K}_{2} \mathrm{O}$, provavelmente devido à presença da muscovita e da biotita. Entretanto, não se pode afirmar que esse é o teor de potássio disponível no mineral, pois essa disponibilidade depende da capacidade de troca iônica e condições químicas para a sua extração. Deve-se atentar para o teor de $\mathrm{Al}_{2} \mathrm{O}_{3}$, cerca de $20 \%$, pois o alumínio em excesso é tóxico e interfere na disponibilidade de outros nutrientes presentes na amostra (Sousa et al, 2007).

\section{Análise do desenvolvimento das mudas.}

Decorrido 1 mês do plantio das mudas, estas foram submetidas a medição de tamanho para comparar as mudas com e sem adição do pó do rejeito. As tabela 3 representa o crescimento das mudas de Pacovan ken.

Tabela 3 - Desenvolvimento das mudas de Pacovan ken

\begin{tabular}{ccccc}
\hline $\begin{array}{c}\text { 100\% substrato } \\
\text { (Altura em } \mathrm{cm} \text { ) }\end{array}$ & $\begin{array}{c}\text { 80\%substrato } \\
20 \% \text { pó do } \\
\text { rejeito (Altura em } \\
\mathrm{cm} \text { ) }\end{array}$ & $\begin{array}{c}60 \% \text { substrato } \\
40 \% \text { pó do } \\
\text { rejeito (Altura em } \\
\mathrm{cm} \text { ) }\end{array}$ & $\begin{array}{c}40 \% \text { substrato } \\
60 \% \text { pó do } \\
\text { rejeito (Altura em } \\
\mathrm{cm} \text { ) }\end{array}$ & $\begin{array}{c}20 \% \text { substrato } \\
80 \% \text { pó do } \\
\text { rejeito (Altura em } \\
\mathrm{cm} \text { ) }\end{array}$ \\
\hline 18,25 & 14,50 & 14,68 & 12,33 & 12,75 \\
\hline
\end{tabular}

Nota-se que o crescimento das mudas com adição do rejeito foi inferior ao da muda apenas com o substrato (humos, vermiculita e areia). O fato se dá em razão do pó do rejeito não possuir os demais nutrientes de interesse para a nutrição adequada das mudas além de 
tornar o solo compacto impedindo dessa forma a boa aeração que proporciona um bom desenvolvimento das raízes das plantas facilitando a absorção dos mesmos.

Para ter-se um crescimento superior ao das mudas sem adição do pó do rejeito é preciso que esse pó seja balanceado com os nutrientes que estejam na faixa de adequação para o cultivo de bananeira, possibilitando também que o solo se torne mais solto e dessa forma, bem arejado.

A Tabela 4 mostra os valores e nutrientes necessários para cultura de bananeira, de acordo com a EMPARN

Tabela 4 - Faixa de adequação para cultura de bananeira

\begin{tabular}{|c|c|c|c|c|c|c|c|c|c|c|c|c|}
\hline \multicolumn{7}{|c|}{ Nutriente $\mathbf{g} / \mathbf{K g}$} & \multicolumn{6}{c|}{ Nutrientes mg/Kg } \\
\hline $\mathbf{N}$ & $\mathbf{P}$ & $\mathbf{K}$ & $\mathbf{C a}$ & $\mathbf{M g}$ & $\mathbf{S}$ & $\mathbf{N a}$ & $\mathbf{C l}$ & $\mathbf{B}$ & $\mathbf{C u}$ & $\mathbf{F e}$ & $\mathbf{M n}$ & $\mathbf{Z n}$ \\
\hline 27 & 2,0 & 17 & 2,5 & 1,5 & 1,5 & - & - & 10 & 6 & 30 & 20 & 15 \\
\hline 35 & 4,0 & 35 & 8,0 & 5,0 & 3,0 & - & - & 25 & 20 & 250 & 200 & 100 \\
\hline
\end{tabular}

Fonte: EMPARN

\section{Análise de absorção de potássio}

Folhas das bananeiras foram levadas para análise de macronutriente com o objetivo de verificar a absorção do potássio presente no pó do rejeito.

A Figura 3 representa graficamente a absorção do potássio pelas mudas de bananeiras Pacovan Ken.

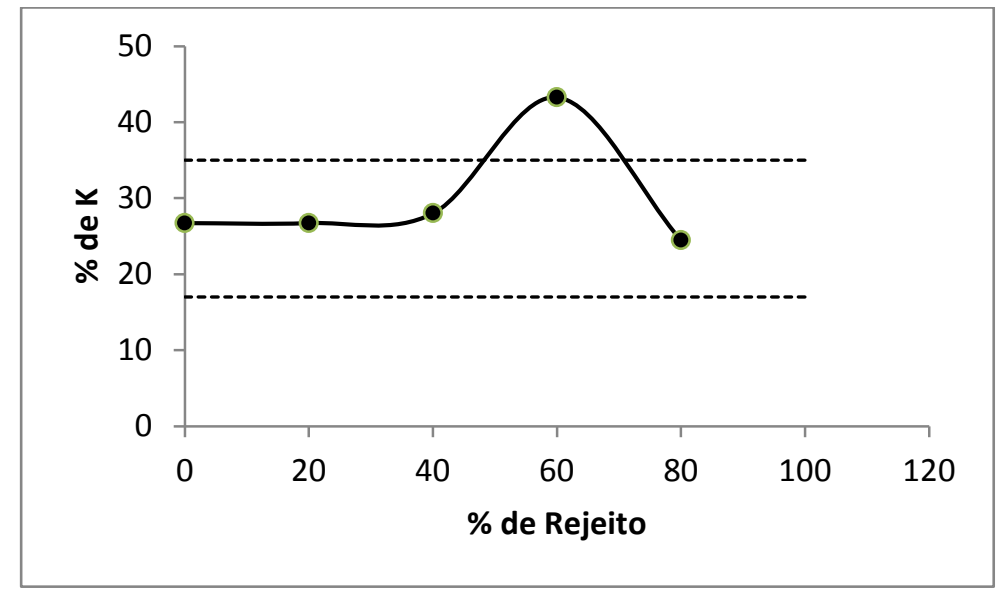

Figura 3 - Representação gráfica da absorção do K pela muda de bananeira pacovan Ken

O gráfico mostra que as mudas de bananeiras absorveram o potássio existente no pó do rejeito. $O$ fato se torna mais expressivo ainda quando adicionado $60 \%$ do pó ao substrato.

Pode-se notar que a muda a qual não houve adição do rejeito também se encaixou na faixa adequada ao cultivo da bananeira, isso se dá devido aos $10 \%$ de vermiculita que compõe o substrato. Como já mencionado, a vermiculita eleva a capacidade de troca catiônica, de médio a alta concentração de cálcio, magnésio e potássio. 
À medida que o pó do rejeito foi incorporado ao substrato o percentual de $\mathrm{K}$ absorvido aumenta, passando de $27,49 \%$ (40\% de rejeito), para $43,26 \%$ (60\% de rejeito). Esse último ponto excede os limites aceitáveis para as mudas.

Com $80 \%$ de pó de rejeito, a absorção do $\mathrm{K}$ atingiu $24,44 \%$, criando uma inflexão na tendência de aumento de liberação com o aumento do percentual de rejeito adicionado. Embora o valor esteja dentro dos limites desejáveis para o cultivo das mudas, ele é inferior ao valor obtido para as mudas sem adição de rejeito, comprometendo desta forma a viabilidade técnica de adotar valores percentuais desta ordem para composição do solo para desenvolvimento da bananeira pacovan ken. Para essa porcentagem, a liberação do potássio torna-se mais lenta devido a escassez do substrato o qual contém a vermiculita que ajuda na liberação do mesmo. A muda também apresentou tamanho inferior devido à problemática da aeração. O pó do rejeito ficou muito compactado impedindo a aeração da raiz da planta o que dificulta também, a absorção dos nutrientes.

\section{CONCLUSÃO}

Após análises dos resultados conclui-se que o rejeito de telha pode ser usado como fonte de potássio por apresentar em sua estrutura cerca de 3,80\% de $\mathrm{K}_{2} \mathrm{O}$.

Quando aplicado, in natura, ao substrato utilizado para o cultivo da bananeira paconvan ken, esse macronutriente é absorvido pelas mudas de forma eficaz ficando dentro da faixa aceitável para o cultivo das mesmas.

O desenvolvimento das mudas foram comprometidas pela deficiência de outros macronutrientes, sendo necessário utilizar, além do rejeito de telha como fonte de $\mathrm{K}$ outras fontes dos demais macro e/ou micronutrientes.

Observou-se também que a introdução do pó do rejeito ao substrato é favorável ao cultivo de bananeira até a proporção de $60 \%$ de substrato e $40 \%$ de pó. Além deste valor, a absorção torna-se muito alta, ultrapassando a faixa desejável (mas podendo ser aplicada em outro cultivo), interferindo na qualidade do fruto.

Para a proporção de $20 \%$ de substrato de $80 \%$ do pó, a absorção ainda se encontra na faixa favorável, porém apresentou uma queda significativa isso devido a alta compactação do pó impedido a aeração das raízes e principalmente devido a falta da vermiculita existente no substrato a qual facilita a absorção do mesmo. Para essa proporção seria necessário um tempo de contato maior do pó com o substrato.

Estudos complementares para determinar a capacidade de absorção para outro tipo de bananeira estão sendo conduzidos e devem ser complementados com um estudo sobre a capacidade de troca iônica do rejeito de cerâmica estrutural em diferentes meios.

\section{AGRADECIMENTOS}

Os autores do trabalho expressam os agradecimentos ao IFRN, em especial ao Labprom e a EMPARN pela viabilização do projeto. 


\section{REFERÊNCIAS BIBLIOGRÁFICAS}

1. LOPES. ASSAD, M.L.; ALMEIDA, J.(2004). Agricultura e sustentabilidade: contexto, desafios e cenários. Ciência e Ambiente, V 29, n1, p1 - 17.

2. DNPM - Departamento Nacional de Produção Mineral. Sumário Mineral 2011. Disponível em: http://www.dnpm.gov.br. Acesso em 13/08/2012.

3. EMBRAPA - Sistema de Produção da Bananeira Irrigada. Disponível em: http://sistemasdeproducao.cnptia.embrapa.br/. Acesso em 03/09/2012.

4. CURI, N,; KAMPF,N.; MARQUES, JJ. Mineralogia e formas de potássio em solos brasileiros. In: YAMADA, T.; ROBERTS, T. L. (Ed.). Potássio na agricultura brasileira. Piracicaba: Instituto da Potassa e do Fosfato; Instituto Internacional da Potassa, 2005. P. 71 - 86.

5. NOBRE, L. L. S.; LEITE, J. Y. P. Análise do rejeito de cerâmica vermelha e sua aplicação como fonte de potássio na agricultura. Revista HOLOS. Natal, v 5. p. 3-9,2011.

6. NACHTIGALL, G.R.; VAHL, L.C. Dinâmica de Liberação do Potássio dos solos da região sul do Rio Grande do Sul. Revista Brasileira de Ciência do Solo. Campinas, v.15, p. 43 - 47, 1991b.

7. REICHENBACH, H.G. van. Factores of mica transformation. In: COLLOQUIUM OF THE INTERNATIONAL POTASH INSTITUTE, 9., 1972. Landshut. Proceedings...Bern: International Potash Institute, 1972. P. 33- 42.

8. SINGH, B.; GOULDING, K. W. T. Changs with time in the potassium content and phyllosollicates in the soil the Broadbalk Continuos Wheat experiment at Rothamsted. Europen Journal Soil Science, Oxford, v. 48, p 651-659, 1997. 